\title{
Arquiteturas da subversão no cinema brasileiro: Que horas ela volta?'
}

ARCHITECTURES OF SUBVERSION IN BRAZILIAN CINEMA: THE SECOND MOTHER

\section{Rafael Tassi Teixeira}

Doutor em sociologia pela Universidade Complutense de Madrid (2004). Vice-coordenador, docente e pesquisador vinculado ao Programa de Pós-Graduação em Comunicação e Linguagens da Universidade Tuiuti do Paraná (PPGComUTP). Professor adjunto da Universidade Estadual do Paraná (Unespar).

rafatassiteixeira@hotmail.com

\section{Sandra Fischer}

Pós-doutora em cinema pela Escola de Comunicação da Universidade Federal do Rio de Janeiro (ECO - UFRJ, 2009) e doutora em ciências da comunicação pela Escola de Comunicações e Artes da Universidade de São Paulo (ECA - USP, 2002). Docente e pesquisadora vinculada ao Programa de Pós-Graduação em Comunicação e Linguagens da Universidade Tuiuti do Paraná (PPGCom/UTP).

sandra.fisher@uol.com.br

Recebido em 28 de fevereiro de 2016. Aprovado em 24 de abril de 2016.

\section{Resumo}

$\mathrm{O}$ artigo trata da potência subversiva que se aloja nas imagens de Que horas ela volta? (Brasil, 2015, Ana Muylaert), particularmente naquelas que dizem respeito à arquitetura da casa e aos espaços da cidade. O filme, que tem lugar em ambientes urbanos típicos da família de classe média alta do Brasil contemporâneo, articula enquadramentos de espaços públicos e privados nos quais se desenvolve uma ação que remete, em certa medida, à dinâmica "casa-grande e senzala" (Gilberto Freyre). O encadeamento cênico apresenta a artificialidade de sistemas socias corrompidos e decadentes e implode, poética e sintomaticamente, as bases anacrônicas que

1 Uma versão preliminar deste trabalho, submetida à AVANCA | CINEMA Conferência Internacional Cinema Arte, Tecnologia, Comunicação/Cine-Clube de Avanca (27 a 31 de julho de 2016, Avanca, Portugal), foi aceita, apresentada em comunicação e publicada nos documentos do evento.

$120 \frac{\text { Comunicação \& Inovação, PPGCOM/USCS }}{\text { v. 17, n. } 34 \text { (120-134) maio-ago. } 2016}$ 
estruturam relações sociais que subsistem e resistem articuladas por meio de mecanismos tacitamente admitidos e reiterados de exploração e segregação consentidas.

\section{Abstract}

This article discusses the subversive power inserted in the images of The second mother (Brazil, 2015, Ana Muylaert, particularly in those regarding the house architecture and the city spaces. The movie, which is set in typical urban environments of the upper middle class families of contemporary Brazil, articulates framings of public and private spaces in which takes place an action that, to some extent, refers to the "master and the slaves" dynamics (Gilberto Freyre). The scenic sequence shows the artificiality of corrupted and
Palavras-chave: Cinema brasileiro contemporâneo. Ana Muylaert. Que horas ela volta? Cidade e sociedade brasileira contemporânea. Arquitetura e subversão.

decadent social systems and implodes, poetically and symptomatically, the anachronic foundations that structure the social relations that survive and resist articulated by implicitly accepted and reiterated mechanisms of consented exploitation and segregation.

Keywords: Brazilian contemporary cinema. Ana Muylaert. The second mother. Brazilian contemporary city and society. Architecture and subversion.

\section{A hora da chegada}

A trajetória da carreira da cineasta Anna Muylaert tem sido caracterizada por obras que primam pela mistura de gêneros que se alternam entre o dramático e o cômico, pela inserção mais ou menos velada de elementos surrealistas e pela presença relativamente discreta da crítica ao caráter perverso e excludente de determinadas facetas dos sistemas sociais vigentes: em seus filmes, sempre ambientados em cenários urbanos da atualidade, trama, personagens e figuras ou elementos de caráter simbólico movimentam-se por entre reviravoltas narrativas que passeiam pelas veredas da comédia, do suspense, do drama - às vezes tangenciando o buñuelesco, como se verifica na figura do cavalo literalmente encantado de Durval discos (2002), presença marcante, de forma explícita ou implícita, em praticamente todas as cenas (FISCHER, 2005) - e quase sempre tratando, criticamente, de normas e convenções sociais invisíveis, tácitas - como se passa em $E$ proibido fumar (2009).

Em Que horas ela volta? (2015), a crítica social a valores anacrônicos ainda em larga extensão postulados por considerável parcela das classes dominantes no Brasil contemporâneo adquire estatura significativa. No filme, ambientado na cidade de São Paulo - basicamente na região dos Jardins, formada pelos bairros elegantes e bem estruturados em que 
transita e reside boa parte da alta classe média paulistana -, Muylaert, conferindo importante destaque ao caráter conturbado e desigual do espaço urbano em que se desenvolve a ação, trata enfaticamente das regras sociais implícitas que regem, regulam e modalizam silenciosamente o cotidiano das pessoas e o curso dos acontecimentos, sem que necessariamente os envolvidos se deem efetiva conta dos diversos mecanismos de coerção e segregação aí implicados.

Na trama, a protagonista Val (Regina Casé) trabalha há mais de doze anos como empregada doméstica da família de Bárbara (Karine Teles) e José Carlos (Lourenço Mutarelli). Sem condições de manter casa própria ou alugada, reside nas minúsculas dependências localizadas nos fundos da ampla e sofisticada propriedade de seus patrões; com o tempo, acabou se tornando também a babá do filho único do casal, Fabinho (Michel Joelsas), a quem se afeiçoou fortemente. O menino, por seu turno, na longa e continuada convivência com Val, estabeleceu vínculos afetivos que não apenas the garantem segurança e espontaneidade, como propiciam frequentes momentos de carinho - aparentemente mais autênticos e intensos do que aqueles que experimenta junto a Bárbara, sua mãe; já adolescente no momento em que transcorre a diegese fílmica, Fabinho tem a mesma idade de Jéssica (Camila Márdila), a filha que Val deixara no interior de Pernambuco, aos cuidados de outra pessoa, na ocasião em que partira em busca de melhores condições de vida. O filme sugere que mãe e filha não mantêm contato frequente, embora Val seja responsável pelo sustento da menina e, mesmo à distância, preocupe-se com ela e tente acompanhar seu desenvolvimento e educação.

O filme nucleariza a condição da dependência nos detalhes das relações entendidas em seus universos de forças dominantes comuns, estabelecidos nos lugares essencializados como "consciência" das posições: a retirante que largara a filha pequena no Nordeste do país, deixando o interior para trabalhar como doméstica em um grande centro urbano no Sudeste, recebe a notícia de que a menina, que não vê há vários anos, almeja tornar-se arquiteta - porque acredita que "a arquitetura é um instrumento de modificação social" - e está a caminho de São Paulo para prestar vestibular na Faculdade de Arquitetura e Urbanismo da Universidade de São Paulo, a icônica FAU da USP. Jéssica será recebida com alegria pela mãe, contente - e algo perplexa - ao saber que a filha percorreria de avião, e não de ônibus, a longa distância que separa os dois estados, Pernambuco e São Paulo.

Nesse sentido, conforme escreve Magnani (1996), a cidade não é apenas um ambiente feito de espacialidades intercambiáveis e circuitos de relação em formas de "pedaços" excludentes. A emergência do urbano que recebe Jéssica tem a ver com escolhas determinadas por territórios invisíveis que restringem a circulação de Val, e que vão sendo percebidos à medida que os estranhamentos ocupam o centro residual da ideia da 
hospedagem: circuitos moldados de trajetos sub-reptícios, repercutidos como "manchas urbanas" (MAGNANI, 1996) que incidem em verticalizações, limites, muros, janelas executadas para o claustro interior, sempre.

A organização métrica cheia de espaços impedidos, de trânsitos mortos, mas resilientes, que parecem vestir a dinâmica das paisagens carregadas de entropismos (DI FELICE, 2009) provenientes de desencontros - nesse sentido, os limites espaciais são estabelecidos para impedir que os corpos se relacionem frontalmente; há arquiteturas mudas, paredes espessas, profundidades remanescentes que são caracterizadas para que os corpos não se iludam sobre suas "consciências posicionais". Distanciamento, insuficiência, familiaridade relativa têm a ver com a perene sensação de que a heterogeneidade provinda da divisão social do trabalho nunca termina de ocupar a impossibilidade com que os muros, ou as "cidades físicas" (SILVA, 2014), revelem as desiguais visões de mundo. A coexistência é, sentidamente, uma conformação de enclaves habitados por trânsitos mudos, por semelhanças deletérias e pelo que é, no filme, o mais indelével: as situações da experiência subjetiva amarrada aos corpos sociais impregnados de seus lugares físicos.'

Pouco a pouco, a imagem da "desmaterialização" (SILVA, 2014) - a noção imaginária dos afetos e do senso de communitas (TURNER, 1974) encarnada em Val - vai sendo revelada pela "materialização" dos corpos sociais, da cordialidade que pressupõe, provavelmente de modo violento, um jogo de abusos redimidos por subjetivizações sempre parciais (o limite dessa arquitetura de sutilezas negadas no interior da casa, e da condição sígnica parcial que esconde uma edificação brutal, é a área de serviço).

"A cidade do tempo vai se sobrepondo à cidade do espaço", escreve Silva (2014). O habitar empático, contrapõe Di Felice (2009), vai se tornando a escrita do estranhamento e do estrangeirismo, da sociedade-pele, do escancarar do desconforto: o urbano, nesse sentido, não é uma anteposição à experiência da casa (de Val) que, após duas décadas, ainda não existe; o "subúrbio" está na casa-grande que exige sua arquitetura liminal, que somente tem sentido no sufocar, no abafamento - sobre o que se verticaliza -, impondo seu castelamento, sua geografia de muralhas soltas, transpostas em ritualizações provisórias, concebidas como situações permanentes de liminaridade imemorial. A casa, descomunal, que acaba se revelando a cidade, em sociabilidade e narrativa mudas, negada para Val - o trânsito, sempre adscrito à vida da família, em suas marcações psicológicas, em seus ritmos espaciais. (O subúrbio, nesse sentido, como reificação das redes de sociabilidade marginais, descontínuas, dentro do tecido urbano da "casa-grande" - os outros empregados, a chegada de Jéssica - naturalizado como pertencimentos permanentes.)

1 Há, nessa ideia do encarceramento, uma vontade, ao mesmo tempo, de impulso e abandono, no cinema brasileiro contemporâneo, conforme desenvolvido por Teixeira (2015). 
Inicialmente, a menina é bem acolhida pelos patrões de Val e também por Fabinho: afável, o casal se mostra surpreso com seus planos e disposição de submeter-se ao concorrido certame da FAU/USP, mesmo concurso que será enfrentado pelo filho de ambos. A hora da chegada é pontuada por imagens em que se destacam as agradáveis impressões de Jéssica com elementos da paisagem urbana de São Paulo, com a beleza da casa em que a mãe atua como doméstica (embora estranhe o fato de Val não dispor de uma moradia que não seja a mesma de seu posto de trabalho). O clima hospitaleiro, as apresentações cordiais, os sorrisos receptivos, as palavras amenas dão o tom às cenas que se sucedem ao momento em que mãe e filha se encontram no aeroporto e acomodam-se no ônibus que conduz a tranquila e bonachona Val e a entusiasmada - e algo reticente - recém-chegada até a o local em que a primeira trabalha e reside.

Não obstante o alvissareiro instante inaugural, à medida que a garota se aloja na residência - e, subvertendo o protocolo, começa tanto a expressar opiniões contundentes (firmes e bem fundamentadas) e a manifestar desejos e intenções (de caráter inusitado no contexto em questão) quanto a ocupar espaços interditos, circulando livremente pelos cômodos da casa -, a situação se altera: instala-se o conflito na família, na dinâmica das relações entre patrões e empregada e no ainda incipiente relacionamento entre mãe e filha.

$\mathrm{O}$ advento invasivo da chegada de Jéssica provoca desarranjos e estranhamentos que desvelam o semblante inamistoso das convenções estabelecidas e tornam explícito o rosto da segregação. O lugar de Val, obviamente, tanto no interior restrito e privado da casa de Bárbara e José Carlos quanto na amplificação do exterior público e turbulento configurado pela metrópole de São Paulo, funda-se como o lugar do subalterno e estabelece-se nas bases da arquitetura do subjugado: daquele que é "como se fosse da família", o conhecido bordão repetido à exaustão por patrões "bem intencionados" a empregados domésticos nem sempre céticos e ainda em muito desavisados de que "como se fosse da família" não está nem perto de ser efetivamente "da família", de pertencer ao grupo com a mesma legitimidade dos demais componentes. Nas casas e apartamentos em que circulam, sua situação é a daqueles que utilizam, cotidianamente, a entrada dos fundos, o elevador de serviço, os (in)cômodos que nas edificações são reservados aos empregados; nas cidades, particularmente em se tratando de países como, entre outros, o Brasil, a posição que ocupam é a dos que obrigatória e permanentemente enfrentam a aglomeração do transporte coletivo, quase sempre precário e desconfortável; dos que vivenciam, cotidianamente, a crônica falta de estrutura que costuma caracterizar a periferia dos grandes centros urbanos.

Isso posto, entretanto, há que ressaltar que contribui para a eficiência das potencialidades cinematográficas e para o adensamento da perspectiva crítica do filme a recusa à utilização de lugares-comuns reducionistas ou rasos: a contingência de a vida particular 
da protagonista de Que horas ela volta? transcorrer empilhada no mesmo local em que a personagem presta serviços profissionais, por exemplo, não faz da personagem uma figura constrangida ou amargurada; por outro lado, tampouco ela se revela estritamente alinhada com o estereótipo do explorado ingênuo e subserviente que não se percebe alijado de seus direitos. Adaptada e conformada ao quarto dos fundos, Val aceita - sem manifestar maiores questionamentos e de uma forma desdramatizada que não parece the ser exatamente incômoda e que mais se aproxima da tranquilidade madura do que da passividade ignorante - o lugar que lhe "cabe" no cotidiano dos patrões, na vida de Fabinho e nos espaços da casa e da cidade que habita. Jéssica, entretanto, abomina e não reconhece essa imposição, não se mostra disposta a fazer concessões que poderiam legitimá-la (minimamente que fosse) e não se amolda, em nenhum aspecto, ao lugar que the seria tradicionalmente reservado na condição de filha da empregada.

\section{A hora do chega!}

Jéssica, personagem que apresenta contornos delineados pela espontaneidade de uma vivacidade insolente e destemida - e algo prepotente, diga-se -, é o elemento estrangeiro atípico que, logo na chegada, fere a distribuição sub-reptícia dos imaginários dominados por linguagens de tolerâncias passivas (nunca há engajamento, nunca há avanço efetivo sobre os dramas encenados, sobrevividos à força da anulação condicional). Ela denuncia e questiona os lugares-comuns dos pertencimentos e não-pertencimentos, as interdições e os espaços ociosos: o "sorvete de Fabinho", sobremesa destinada exclusivamente aos membros da família, revela-se mais apetecível e saboroso do que aquele reservado aos empregados; o quarto de hóspedes, desocupado e amplo, apresenta instalações atraentes e muito superiores ao minúsculo e abafado quartinho que a resignada Val habita na residência dos patrões - e que, de acordo com as expectativas, deveria dividir com a filha: colchão estendido no chão ao lado da estreita cama de solteiro, ventilação insuficiente, iluminação parca, conforto duvidoso; as conversas com Fabinho e amigos, em brincadeiras na piscina, bem como o compartilhamento com José Carlos, propiciado pelos diálogos reflexivos e por incursões pela cidade, mostram-se experiências mais sedutoras e estimulantes do que a convivência com as colegas da mãe.

Desde o conjunto de situações reescritas para pensar o plano das circulações dos corpos - a sua suspensão relativa -, a máquina de indiferenças travestidas de diferenças sutis age onde tudo é revelado por sua grafia oculta, sempre ociosa, determinada pelo desequilíbrio e pela paternalização intoxicante: as relações de dominação são carregadas de pseudointeresse e pseudoproteção, as ideias de emancipação não são descobertas das suas 
impossibilidades, os lugares são mantidos pela impermeabilização, pelo acesso restrito e pela perenidade das ocupações. Os sistemas de hierarquias transversalizadas evocam, em Que horas ela volta?, as relações que se apresentam, de forma frequentemente edulcorada e por vezes mesmo algo romântica, na narrativa ensaística de Casa-grande \& senzala (FREYRE, 2015), nas quais o subalterno - como ocorre com o retirante, o estrangeiro - é tolerado desde que "saiba seu lugar" e nele se mantenha.

Diferente do que acontece em diversos outros lugares - por exemplo, Estados Unidos, Canadá ou países europeus -, o Brasil mostra-se ainda um reduto, um manancial de servidores domésticos mais ou menos prontos a aceitar os mandos e desmandos de patrões representantes das classes média e alta que, em geral, em certa extensão ainda colocam seus empregados em estado de, digamos, confinamento - destinando-lhes banheiros exclusivos e quartos de dormir acanhados, ambos quase sempre diminutos e carentes de luz e ar, encaixados em áreas localizadas nos fundos ou junto às áreas de serviço de casas e apartamentos. Sob o pretexto de resguardar privacidades, esses são procedimentos que não deixam de funcionar como mecanismos coercitivos que marcam e delimitam territórios e, assim, reforçam sistemas de segregação (a desproporção na distribuição e na qualidade dos espaços, diversas vezes ressaltada no filme, é enfatizada quando Jéssica, com planos de se tornar arquiteta, detém-se a examinar as plantas da casa dos patrões da mãe). No que se refere a funções, obrigações e horários de expediente - não obstante as recentes iniciativas de regulamentação profissional da categoria em curso no país, os direitos trabalhistas nem sempre são devidamente observados e respeitados (a esse respeito vejam-se, entre outras, as cenas que mostram Val ocupando-se de Fabinho em seu tempo livre).

A figura da filha de Val, subversiva, não demonstra a menor tolerância a interdições frustrantes e nem exibe qualquer inclinação a suportar o status quo. Determinada e cheia de planos, foge completamente ao estereótipo do desfavorecimento, da desinformação, da vitimização. Avessa ao conformismo materno, é com naturalidade e desenvoltura que transita pelos espaços fílmicos aceitando as tímidas gentilezas de José Carlos, compartilhando as criancices de Fabinho, ignorando as suscetibilidades da dona da casa e as admoestações premonitórias de mãe. As plateias que eventualmente se reconhecem nas figuras de Bárbara e de sua família são confrontadas com o estranho ${ }^{2}$ que se aloja na imagem algo incômoda apresentada na cena em que a adolescente e o pai de Fabinho, isolados na imensa sala de um apartamento - vazio e aparentemente em avançado estado

2 Os termos "estranho" e "estranhamento", neste trabalho, estão sendo utilizados na perspectiva conceitual em que são definidos por Sigmund Freud (1972, p. 277) segundo o qual o estranho é entendido como "aquela categoria do assustador que remete ao que é conhecido, de velho, e há muito familiar'. 
de deterioração - localizado no alto do tradicional Edifício Copan ${ }^{3}$, dedicam-se a contemplar a vastidão configurada pela vista da cidade e entregam-se a reflexões e posturas de compartilhamento que, ao culminarem em abraço e beijo que inicialmente sugerem a obviedade do assédio - preconceituosamente esperado -, acabam revelando o inusitado da fragilidade latente e da busca desacertada. O mesmo estranhamento tende a repetir-se na breve sequência, genuína e densamente poética, em que José Carlos, posto de joelhos no chão na cozinha de casa, suplica a Jéssica que se case com ele - e, diante da perplexidade da menina, rapidamente recobra o senso crítico e afirma estar brincando. O mesmo estranhamento amplifica-se, mais ainda, na cena em que Jéssica e Fábinho, sentados à beira da piscina (esvaziada por ordem de Bárbara, que pretextara ter visto um rato na água após ter flagrado a filha da empregada ali mergulhada), trocam ideias e compartilham um cigarro de maconha: "Você acha que eu sou um rato?" pergunta a menina ao companheiro, entre irônica e contrafeita.

O filme desvela a corrosão da modalidade contemporânea e urbana da antiga (?) dinâmica "casa-grande e senzala" característica do Brasil colônia, patriarcal e conservador. Atribuindo à personagem de Jéssica uma firme e crescente vontade de questionamento e reformulação das geografias de poder acomodadas em seus intramuros caseiros, confere visibilidade às assimetrias mudas, indivisíveis e adensadas pela formalização dos desequilíbrios, das decadências das posições e do sem sentido das hierarquias - elementos sempre refratários ao mais mínimo movimento de relativização, custodiado que é pela falta de força em prolongar, mesmo admitindo os privilégios, as reconstruções necessárias para solver o dilema das mencionadas assimetrias (como se constata nas trocas verbais e nos diálogos confessionais - quase sempre abruptamente suspensos ou interrompidos - que acontecem entre José Carlos, o dono da casa melancólico e algo depressivo, e a vibrante forasteira Jéssica).

3 É significativa no filme a presença do Edifício Copan, projetado pelo arquiteto Oscar Niemeyer na década de 1950. O prédio, não obstante seu inegável valor arquitetônico, como ícone representativo de um tempo remoto (no qual a capital de São Paulo começava a transformar-se em grande metrópole e passava por mudanças tais como adensamento populacional, expansão de malha urbana, verticalização, especulação imobiliária na região central, fortalecimento da economia, deslocamento do setor industrial para fora do perímetro urbano etc.), hoje se constitui, de certa forma, como um anacronismo urbano. Na diegese fílmica, pode ser lido como uma metáfora da figura da extemporaneidade, do ultrapassado, daquilo que já foi (o conceito urbano que embasa o hoje depauperado edifício não cabe mais na contemporaneidade). Postada no cenário sugestivo do edifício em questão, a figura de Jéssica (a filha da empregada, bem preparada e prestes a submeter-se ao vestibular de arquitetura), lado a lado com a figura de José Carlos (o patrão, artista frustrado e estagnado em seu estado emocional depressivo, herdeiro de um patrimônio que não foi por ele construído), em certa extensão torna evidente o anacronismo de certos sistemas de relações ainda vigentes - e sinaliza a chegada de novos tempos. 
A incapacidade em promover rupturas longas, nesse sentido, caminha para a disseminação de uma infinidade de espelhos, mantidos reversos e administrados pelo ocultamento da sensibilidade autêntica, potências de um falso que parece sempre vencer a autocrítica da imagem maior: o fato do acobertamento e da impunidade dos ritmos, de seus rituais emudecidos, da servidão dos estados paralisantes porque sempre mais decompostos. Não há ação igualitária (mesmo braçal), por parte dos patrões, porque a verdadeira lei é concebida como um disfarce, uma alteridade que não existe como partilha e sim como aniquilação, desenhada na incapacidade de perceber que o que define as fronteiras não é a fala, não é o cortejamento (não é o afeto ressentido e exigente), mas a historicização (nula, anestesiada quando minimamente assistida) da autoimagem, mantida sempre em segredo em suas fissuras, em seus acordos tácitos (que vencem qualquer possibilidade de permeabilização dos preconceitos, medos íntimos e estranhamentos recíprocos) - como as qualidades secretas de um patrão artista sufocado que jamais saiu ao mundo, preferindo pré-existir na mediocridade 4 .

O estranhamento, nesse sentido, não funciona tão somente como mera variante da insuficiência do afeto (para redesenhar fronteiras); configura-se, sobretudo, como uma pele que se entende mensageira de uma proteção da imagem, em todo e qualquer caso, vista como servidão posicional. A incapacidade de ler as subjetivações desde uma escuta não programada, aliada à falta de uma crítica frequente a toda a ordem pré-concebida, indisposta, dos afetos, propulsam a visão de possessão física antecedida pela possessão conceitual das distâncias desses dois mundos, domínios de artefatização sempre incompleta.

Ao tentar desglossar assimetrias, nesse âmbito, a diferença, que está na capacidade de emancipação, regressa à recusa dos espaços intersticiais, negados porque a visão pessimista e prepotente (o outro não têm sonhos, o outro não tem vida antes e nem depois) prevalece sobre a imagem da integração. Nesse sentido, há um convívio multiculturalista, apenas admitido a partir de indivisibilidades e sustentações caracterizadas por simbolizações diferenciadas. A anomia dos discursos, que sempre são de outrem, alimenta-se desse outro que não consegue sobreviver dentro de um próprio, propulsando, assim, os projetos de possessão ritual e a possibilidade, convencional, alegórica apenas, da tentativa, se ela existisse, de compreender esse outro.

Não há nenhuma vontade, portanto, de produzir diferenciações e estranhamentos efetivos, derivados de um interesse etnográfico e desrepresentacional: a necessidade de assegurar as posições mantém uma mesma metáfora assistida pela gravitação ao redor de

4 Como as qualidades secretas de um patrão artista sufocado que jamais saiu ao mundo, preferindo pré-existir na mediocridade. 
um self possessivo (CLIFFORD, 1988) e sem experiência estésica (sem, portanto, devires ou linhas de fuga).

O outro lado do exercício da identidade, em Que horas ela volta?, é a incompreensão, nesse caso, da violência de negar ser habitado por afetos (afetos outros, amparados apenas por suas faltas). Observa-se que a precariedade laboral é apenas uma das facetas da dissimulação do imaginário da relação, pois a normalidade parece ser estabelecida a partir de um permanente estado de tensão sub-reptício que demarca a fronteira entre o eu e o outro, sobretudo na incapacidade de promover sentidos sociais para uma relativização duradoura e crítica da questão da posição das presenças.

Quando a personagem de Jéssica invade a cena e desestabiliza os finos sentidos e as relações de dominação e servidão entre patrões (Bárbara e José Carlos) e empregada (Val), os universos de emulação fraternal entre os corpos pedem remissão - mas a imagem da metáfora da fraternidade desaparece assim que um afeto é suspendido; no centro da narrativa, a partida de um objeto de cuidado e amor (Fabinho) recoloca a dimensão afetiva em seu lugar de origem. O filme, nesse aspecto, possui uma revisão da pragmática do abandono e da transferência por ausências: o consolo (prestar cuidados e atenções a um filho que não é seu) é o outro lado da relação de uma falta como partida; a narrativa de Que horas ela volta? descansa, portanto, na imagem, poderosa, do sofrimento entre as relações livres (Fabinho) e as condicionadas pela origem social (Jéssica). Se, como diz Viveiros de Castro (2005, p. 157), "relacionar é assemelhar, unificar, identificar", o filme produz a consciência da relação, por parte de Val, a personagem principal, apenas no momento final, quando uma partida algo inesperada (de Fabinho, rumo ao novo idealizado da Austrália) e o entendimento de uma chegada definitiva (Jéssica, adentrando a universidade, e a própria Val, descobrindo a existência do neto insuspeitado) dissecam o universo das metáforas fraternais (a dominação por afetos). Os constrangimentos dissimulados entre as relações patrões-empregados, no filme de Muylaert, escondem identidades sub-reptícias, compreendidas no modelo de relações sociais que não observam seus estados de codependência: o fibroso ordenamento das individualidades redime a falta que implica uma (des)identificação parcial do pertencimento de origem. A afeição pela criança que não é sua, mas que é acolhida como identificação irrestrita, é a base do sentido da permanência em outro espaço (solitário, indivisível, indisponível) que entrelaça as situações carinhosas com as diferenças (sempre sutis, sempre mais duras) de marcação dos corpos e de seus rígidos lugares de inscrição (que, de forma ambivalente, parecem distantes dos desejos dos indivíduos). As distâncias sociais, desse modo, parecem nunca ser superadas pela necessidade, maior, de os atores envolvidos desenvolverem suas personas imaginárias. O afeto é, dessa forma, a causa e o desconhecimento da dominação, porque impede 
o reconhecimento da medida exata do que é o ato contínuo da despersonalização: anulam-se corpos, pois há um acúmulo pulsional, personagens que necessitam dos outros para fazer (ou prosseguir fazendo) viver as metáforas da fraternidade e da harmonia presencial. Sob o peso dessas locuções (viver na direção de sujeitos que não praticam objetificações), transforma-se a lógica dos imaginários no âmbito das relações, distantes das suas especificidades e de seus lugares históricos de rejeição e abandono ${ }^{5}$.

Philippe Lacoue-Labarthe e Jean-Luc Nancy (2013) expõem essa questão ao pensar o sítio das dificuldades relativas ao trânsito da identidade (socius) como um lugar de apoio à força do desamparo e à possibilidade sempre aberta das identificações. A angústia individualista é concebida, no filme, por sistemas de relações que provavelmente duram mais que os corpos que os tornam presentes. Há, por exemplo, na personagem do patrão (José Carlos), uma vontade relativista, um desespero da transformação (ele parece devotar sentimentos fortemente ambíguos em relação a Jéssica) e reproduz, em um trânsito similar (em uma identificação aberta e muito próxima à que Val faz em relação a Fabinho), o que é transmitido (a herança familiar, os lugares de empoderamento essencializados), estando apenas idealmente preparado para ver o que se observaria, de maneira racional, a posição "confortável" no sistema de dependência ${ }^{6}$.

Não obstante, quando tensionadas, quando descobertas, as relações subvertidas e suas frequências livres, dispostas a estar mais longe do regime de fronteirizações (a casa-grande indo à senzala e a senzala engolindo a grande-casa), são solvidas pela violência como instrução de um socius sintomático: a potência (da relação) é sempre mais proibitiva para que a intimidade seja salvaguardada; as vontades (de emancipação, de trocas mútuas) perduram apenas o tanto que são negadas pela externalização da diferença, ipsis litteris, porque a exposição de que a diferença é do domínio das percepções (e não da essencialidade) acaba transportando a mesma ao universo de uma única operação: a diferença não é vista como uma possibilidade além do compartilhamento, porque as relações, por serem premidas por uma identidade absoluta, acabam sendo concordantes com uma lógica da dependência ${ }^{7}$. A sensibilidade como uma troca expressiva e realizável é dissolvida, dessa maneira, pela força da identidade: as relações não podem ser contaminadas por afetos comuns, por presenças reconhecidas apenas em suas faltas (e não apenas

5 A lógica dos imaginários predispostos a ser encarnados como reais é, em certa medida, a mesma lógica que expõe Sibilia (2008) dos "sobjetos": sujeitos (outros) investidos de funcionalidade, e objetos (materialidades, condições) imantados de pessoalidades.

6 Em determinado momento da diegese José Carlos admite a Jéssica, abertamente: "Não tenho dinheiro. Herdei tudo isso".

7 Que é, na esfera das lógicas sociais, uma codependência negativa - "potências do falso" (DELEUZE, 1990) que representa a si mesmo em uma relação objetificada por força ou afeto (noção de fetiche).

130 Comunicação \& Inovação, PPGCOM/USCS 
físicas), mas se tornam assimetricamente desfeitas (e a lógica principal é a tentativa de reequilíbrio dessas forças) pela durabilidade das negações ${ }^{8}$.

A precocidade dos laços e a clandestinidade dos apegos, feitos algo livremente na solidão da casa, no filme de Muylaert, apresentam a dissecação de uma sociedade carregada de irrupções e descompassos entre a admissão da alteridade, pela via do "pessimismo sentimental" e pela clausura dos reconhecimentos (os mais difíceis) que mostram, não obstante, o quão mudos, parciais, transitórios, são os ensaios sobre a iniquidade das relações quando desfeitas de seus nomes (das durações de seus motivos, dos usos, para os dois lados, dos processos de agenciamento). Os paradigmas sobre as sentidas (i)mobilidades clássicas da realidade social brasileira, desde o comum da repetição - a sobrevivência do sistema de diferenciação sem diferenças, por um espelhamento omisso, baseado em uma ideia de sociabilidade frontal e sem preconceitos - são dissolvidos, na consecução da crise do imaginário, pela anacronia da metáfora do relacionamento "cordial", "assentido" e "participativo".

\section{Afetos fenecidos ou potência de subversão?}

Os afetos, em Que horas ela volta?, são instruídos para suspender ou anular, momentânea e provisoriamente, a origem da dominação. Da mesma forma, o sistema de constrangimentos é desenvolvido como falta entre as diferenças incomensuráveis (negar os afetos, desestabilizá-los por sentimentos comuns e inscrevê-los como uma condição, possível ou não, mas sempre posterior à contratualidade correta), e sublinhado pelos efeitos da ruptura temporária e passageira de uma incomunicabilidade maior, obtida pelo imperativo da proximidade (dos corpos e de suas carícias). Esse sistema nunca é modificado, reestruturado e reescrito pelos resultados da ruptura duradoura implicada no abandono e na entrega. As hierarquias dessas relações, instigadas também por afetos mudos, não são violadas por suas regras de intolerância de partida (a casa-grande não vai à senzala para romper seus muros nem a senzala se introduz na casa-grande, tal como faz a personagem de Jéssica, para desvelar recônditos e questionar os volteios de seus labirintos).

É inegável, entretanto, que o expressivo encadeamento de cenas e sequências assinaladas pela marca indelével de elementos de caráter significativamente desestabilizador ou estranho - tais como o cessamento da estranha ligação maternal entre o filho da casa e a

8 Os dez anos sem ver a filha, por parte de Val, nesse sentido, revestem-se da mesma crueza que se observa na negação do abraço entre mãe e filho, para além do desconhecimento, entre Bárbara e Fabinho; as relações entre consanguíneos, paradigmaticamente, sofrem da (in)fiabilidade das dependências recíprocas. A tradução dessa ideia é que o paradigma da cordialidade, no fundo, tem mais força que as relações comuns, pois a natureza da afetividade parece se dirigir por uma condição de desvestimento/investimento mais livre, menos programática nas identificações que "saltam" o sistema de parentesco e relações. 
empregada doméstica, abruptamente interrompida pela partida do garoto rumo ao exterior, reforçado pelo afastamento de Val que decide deixar o emprego, ou como a aura incipiente de eroticidade e desejo reprimido que se estende por entre Jéssica e José Carlos -, associado ao inusitado ou inesperado que se aloja nos detalhes de cada quadro - os movimentos da coreografia à moda "jogo de xadrez", repetidamente ensaiada pela inquietude das mãos de Val no preto e branco do aparelho de café (com sua garrafa térmica deslocada sim, em deslugar talvez ${ }^{9}$, mas soberana em sua permanência altiva, verticalizada e insistente), por ela presenteado e depois subtraído à patroa; a presença incômoda do 'rato-Jéssica'; a quase-entrega do patrão José Carlos, em sua maturidade desempoderada, posto de joelhos frente à adolescência irreverente de uma Jéssica atônita (e supostamente subalterna); e, nos momentos finais, o passeio inaugural dos pés de Val explorando a piscina interdita (vagando imersos em banho tardio na água rasa) -, indica e configura pontos de corrosão irreversível no sistema vigente e revela uma potência subversiva nas imagens do filme de Muylaert.

Em que pese a relativa leveza com que a trama é conduzida, a comicidade por vezes óbvia de determinadas sequências e o emprego de alguns outros recursos que eventualmente podem ser entendidos como elementos característicos do cinema narrativo industrial, a poeticidade delicada e reflexiva das imagens de Que horas ela volta? acentua, paradoxalmente, o devir mudança implicado nas cenas e passa ao largo da superficialidade das concessões, das rendições ao clichês, dos esquemas conciliatórios: não há conclusões definitivas, por exemplo, e nem final feliz. Fica-se sem saber, por exemplo, como Val pretende pagar as contas e sustentar a si, a filha e o neto; se Jéssica vai conseguir ultrapassar a segunda e derradeira fase, decisiva, do vestibular da FAU; se não vai acabar repetindo, em certa medida, a trajetória da mãe, sendo forçada a submeter-se a posições subalternas por necessidade de sobrevivência; se as relações entre mãe e filha serão fortalecidas ou definitivamente deterioradas. Da mesma forma, ignora-se o que vai ser de Fabinho, sozinho em terra estrangeira, ou a que termo chega o depauperado casamento de Bárbara e José Carlos.

9 A situação de deslugar, basicamente definida pelo nem/nem, é uma posição que implica, em termos da relação entre um dado espaço situacional e seu ocupante, des-acerto, des-encaixe. O consequente desajuste proporcionado por concomitante alojamento/desalojamento funciona como motor de um movimento desestabilizador que constitui um ocupante permanentemente assolado pelo desconforto e perturbado pelo estranhamento (FISCHER, 2013). A situação da garrafa, no contexto do filme, na medida em que é parte do aparelho de café, com suas xícaras e pires, mas não cabe direito na bandeja destinada a conter o conjunto todo, pode ser entendida como correlata à situação da protagonista no âmbito da casa e da vida da família que serve.

$132 \frac{\text { Comunicação \& Inovação, PPGCOM/USCS }}{\text { v. 17, n. } 34 \text { (120-134) maio-ago. } 2016}$ 
De certo, sabe-se apenas que a Val retirante conseguiu, finalmente, um teto seu na cidade por ela escolhida. (Na periferia, sim, mas no alto do morro: são ascendentes as escadas que levam a casa.) E que, na cozinha que ali é a sua, o preparar e servir um café fresco em xícaras - subtraídas e que "jogam" xadrez - não se reduz a uma obrigação servil, mas sim a uma celebração de encontro e afeto entre pessoas próximas que se fizeram distantes e que se reencontram no ritual de compartilhamento da bebida. No ar, por entre labirintos geográficos e arquitetônicos marcados pela poluição da metrópole e pela claustrofobia dos interiores, volteiam vapores - diáfanos - de algo que começa a cheirar bem. Imagens que prenunciam - anunciam, talvez? - a hora em que ela volta.

\section{Referências}

CLIFFORD, J. Dilemas de la cultura. Barcelona: Gedisa, 1988.

DELEUZE, G. A imagem-tempo. São Paulo: Brasiliense, 1990.

DI FELICE, M. Paisagens pós-urbanas: o fim da experiência urbana e as formas comunicativas do habitar. São Paulo: Annablume, 2009.

FISCHER, S. Durval discos: cinema e estranhamento. In: CATANI, A. M. et al. (Orgs.). Estudos Socine de cinema, ano VI. São Paulo: Nojosa, 2005. p. 285-292. Disponível em: < http:// www.socine.org.br/livro/vi_estudos_socine.pdf>.Acesso em: 1 jun. 2016.

. Silêncio, melancolia e perplexidade: a poética do deslugar no cinema contemporâneo. In: CAPUCHO, R.; VALENTE, A. C. (Orgs.). Avanca i cinema 2013. Avanca: Cine-Clube de Avanca, 2013. p. 773-778.

FREUD, S. O estranho. In: . Obras psicológicas completas de Sigmund Freud, vol. XVII. Rio de Janeiro: Imago, 1972.

FREYRE, G. Casa-grande \& senzala: formação da família brasileira sob o regime da economia patriarcal. São Paulo: Global, 2015.

LACOUE-LABARTHE, P.; NANCY, J. La panique politique. Paris: Christian Bourgeois, 2013.

MAGNANI, J. G. C. Quando o campo é a cidade: fazendo antropologia na metrópole. In: MAGNANI, J. G. C.; TORRES, L. L. (Orgs.). Na metrópole: textos de antropologia urbana. São Paulo: Edusp, 1996.

SIBILIA, P. O show do eu: a intimidade como espetáculo. Rio de Janeiro: Nova Fronteira, 2008. SILVA, A. Imaginários, estranhamentos urbanos. São Paulo: Sesc, 2014.

TEIXEIRA, R. T. Paisagens da crise e identidades de abandono no cinema brasileiro contemporâneo. FAP - Revista Cientifica, Curitiba, v. 12, p. 263-276, jan./jun. 2015. Disponível em: $<$ http://www.fap.pr.gov.br/arquivos/File/Cientifica12_CompletaCorrigida.pdf $>$. Acesso em: 1 jun. 2016. 
TURNER, V. O processo ritual: estrutura e anti-estrutura. São Paulo: Vozes, 1974.

VIVEIROS DE CASTRO, E. Equívocos da identidade. In: GONDAR, J.; DOBEDEI, V. (Orgs.). O que é memória social? Rio de Janeiro: ContraCapa, 2005. 